\title{
Percepções dos tutores presenciais sobre a formação inicial de professores de Química em EaD ofertada pelo IFMT
}

Perceptions of attendance tutors on early chemistry teacher training in DE offered by the IFMT

\author{
Marcelo Franco Leão ${ }^{1}$ \\ Eniz Conceição Oliveira² \\ José Claudio Del Pino ${ }^{3}$
}

\section{Resumo}

São muitos os atores envolvidos em um curso de licenciatura na modalidade da Educação a Distância (EaD), dentre os quais, nesse texto, destacam-se os tutores presenciais. As posições e responsabilidades assumidas, além das atribuições e funções desempenhadas, os tornam observadores privilegiados. Assim, o objetivo deste estudo foi investigar as percepções dos tutores presenciais do Curso de Licenciatura em Química em EaD, ofertado pelo IFMT, sobre os desafios que encontram nesse percurso, as lacunas que identificam no curso e os conhecimentos proporcionados aos futuros professores. Realizada durante o primeiro semestre de 2018, esta pesquisa caracteriza-se como descritiva e exploratória, com abordagem qualitativa. Dos 16 tutores atuantes no curso, 8 deles aceitaram participar voluntariamente da pesquisa. Para coletar dados foi utilizado um formulário eletrônico contendo seis questões abertas. Os dados coletados foram analisados por meio da técnica conhecida como análise de conteúdo. As categorias identificadas foram: desafios existentes neste processo formativo; dificuldades ou lacunas identificadas no decorrer do curso; e conhecimentos proporcionados aos futuros professores de química. Com estas percepções é possível compreender como está ocorrendo o processo formativo no IFMT, sendo que tais informações poderão possibilitar o planejamento de ações que promovam melhorias no curso.

Palavras-chave: Educação a distância, Formação de professores, Tutoria.

\section{Abstract}

Several are the players involved in a licentiate degree course in the Distance Education (DE) modality, among which are the attendance tutors, who take the spotlight in this text. The positions and responsibilities taken, as well as the attributions and functions performed,

\footnotetext{
${ }^{1}$ Instituto Federal de Mato Grosso Campus Confresa | marcelo.leao@cfs.ifmt.edu.br

2 Universidade do Vale do Taquari | eniz@univates.br

${ }^{3}$ Universidade Federal do Rio Grande do Sul | delpinojc@yahoo.com.br
} 
make them privileged observers. Thus, the objective of this study is to investigate perceptions of the DE Chemistry Licentiate Degree Course, offered by the IFMT, attendance tutors on the challenges faced along this trail, the gaps they identify in the course and the pieces of knowledge provided to the future teachers. This research took place during the first semester of 2018 and is characterized as descriptive and exploratory from a qualitative approach. From the 16 tutors who work in the course, 8 volunteered to take part in the research. For data collection, an electronic questionnaire was utilized that contained six open questions. The data collected were analyzed through the technique known as content analysis. The categories identified were: existing challenges in this training process; difficulties or gaps identified throughout the course; and pieces of knowledge provided to the future chemistry teachers. From those perceptions, it is possible to understand how the training process occurs at the IFMT, and that information may allow for planning actions to promote improvements to the course.

Keywords: Distance Education, Teacher Training, Tutorship.

\section{Introdução}

A Educação a Distância (EaD) é uma modalidade de ensino que facilita o acesso das pessoas ao Ensino Superior, pois rompe com os limites impostos pelo tempo e espaço geográfico. Seu surgimento teve a premissa de democratizar o acesso e a permanência nas instituições de ensino superior e, consequentemente, uma oportunidade de promover construção de conhecimentos (SILVA; NUNES, 2014). Além disso, a EaD proporciona novos espaços formativos, que não se limitam apenas ao suporte de novas tecnologias ou a materiais didáticos digitais, mas articula os elementos presentes neste processo educativo, dentre os quais, tutores ganham destaque neste texto.

Referente à formação inicial de professores de química em EaD, Silva e Fireman (2013) apontam que esses cursos precisam superar a racionalidade técnica que alicerça separadamente a construção de conhecimentos específicos e pedagógicos desvinculados entre si, com poucas oportunidades para reflexão, ou seja, uma formação praticamente despreocupada com as necessidades existentes na educação contemporânea. Baseados em pressupostos teóricos e documentos legais, os autores defendem uma formação de professores baseada na racionalidade prática fundamentada na reflexão, que ultrapasse acumular conhecimentos e que possibilite estabelecer relações entre conceitos específicos, pedagógicos e transposição didática.

No estudo realizado por Silva e Fireman (2013), foi observado qual a posição adotada no curso de Licenciatura em Química da Universidade Federal do Rio Grande do Norte (UFRN), ofertado na modalidade EaD, sobre a racionalidade dominante, técnica ou prática. Em outras palavras, a intensão foi observar se o curso prioriza o acúmulo de conhecimentos ou se busca meios para promover uma formação reflexiva. Os resultados obtidos apontaram que a formação proporcionada pelo curso é influenciada pela racionalidade técnica dos tutores que atuam neste curso.

Por sua vez, Santos (2017) realizou uma investigação na perspectiva de análise comparativa, com professores de química atuantes em escolas de diferentes contextos sociais, cujos resultados apontaram que muitas de suas práticas foram influenciadas por suas respectivas formações iniciais. Assim, o autor defende que o modelo de formação adotado pelos cursos de licenciatura representa importante fator para evitar a 
predominância da concepção uniforme sobre as práticas pedagógicas, ou seja, é preciso considerar os diferentes contextos sociais e orientar o ensino de maneira a atender às necessidades dos estudantes.

Outro estudo envolvendo a influência dos tutores durante a formação inicial de professores de química, foi o desenvolvido por Oliveira et al. (2013), que investigou o papel desses profissionais no curso em EaD de Licenciatura em Química da Universidade Federal de Minas Gerais (UFMG). Na ocasião, foram consideradas as experiências ocorridas no decorrer do curso, sob o ponto de vista dos próprios tutores do curso. As dificuldades que os investigados relataram referem-se mais ao campo formativo do que ao técnico, ou seja, os tutores apontaram como ações mais relevantes e exigentes para o processo formativo dos futuros professores de química, o apoio e a orientação didática que necessitam prestar para atender as necessidades desses estudantes.

Corroborando as constatações dos estudos supracitados, Acosta et al. (2015) defendem a importância da presença e da atuação de tutores para a realização de cursos em EaD. Em seus estudos, os autores observaram que a tutoria no Curso de Licenciatura em Química, ofertado pelo Instituto Federal de Educação, Ciência e Tecnologia de Mato Grosso (IFMT), na modalidade EaD, assume um papel de destaque e protagonismo, pois são eles os atores que interagem e estabelecem contatos mais efetivos com os estudantes do curso.

O objetivo desse estudo supracitado foi analisar o processo de precarização do trabalho docente pela redução do professor a tutor. Foi possível investigar, por meio dos documentos institucionais e de relatos dos atores envolvidos, quais atribuições e qual o reconhecimento que os tutores possuem nesse curso. $O$ estudo revelou que os tutores do curso não são reconhecidos como professores e que não recebem a formação apropriada para trabalhar com a formação inicial de professores na modalidade EaD.

Essa falta de reconhecimento do papel pedagógico que os tutores desenvolvem nos cursos de Licenciatura em Química em EaD necessita ser superada. Além de valorizar esses profissionais, outra ação que pode contribuir na formação inicial é proporcionar espaços para que os tutores manifestem suas observações e concepções sobre o andamento do curso que acompanham. Nesse sentido, a proposição para o desenvolvimento do presente estudo aproxima-se daquele desenvolvido por Caetano e Rezende Junior (2009), por meio do qual investigaram a visão dos tutores no curso de Licenciatura em Física, da Universidade Federal de Itajubá (UNIFEI) sobre os principais elementos presentes na EaD: estudantes, professores, conteúdo e ambiente de aprendizagem.

Diante do exposto, a presente pesquisa procurou investigar junto aos tutores presenciais do Curso de Licenciatura em Química em EaD do IFMT, quais desafios encontram ao desempenhar a tutoria durante o processo formativo, quais as dificuldades ou lacunas identificadas no curso e quais os conhecimentos proporcionados aos futuros professores de química.

Esta investigação foi motivada no decorrer do desenvolvimento da pesquisa de doutorado que investiga os saberes docentes construídos no decorrer desse curso, a qual será apresentada no Programa de Pós-Graduação Stricto Sensu em Educação em Ciências: Química da Vida e Saúde (PPGQVS), da Universidade Federal do Rio Grande do Sul (UFRGS). Este estudo contou com subsídio financeiro do Edital de Convocação 069/2018 do PROPES / IFMT e do apoio do IFMT referente à bolsa de doutorado do primeiro autor (Edital de Convocação 079/2016). 


\section{EaD e a democratização do acesso ao Ensino Superior}

A EaD é uma modalidade de ensino mediada por tecnologias que permitem o aprendizado e o aperfeiçoamento profissional nas diferentes áreas do conhecimento. Assim, a EaD tem se tornado uma alternativa viável a muitas pessoas nas últimas décadas, porque nela o estudante tem a capacidade de gerenciar seu próprio aprendizado, ou seja, ele tem uma autonomia que possivelmente não teria em uma formação presencial, por conta da administração de seu tempo disponível (SILVA; NUNES, 2014).

Quando se trata da historicidade da EaD, Borges (2015) discute o fato de que, na década de 1960, houve, no Brasil, um esforço oficial, por parte dos órgãos governamentais, pela implementação de projetos nessa modalidade de ensino. Ele ainda argumenta sobre a falta de sucesso das primeiras apresentações do projeto, contudo observou que desde o início, tais projetos visavam a universalização da educação básica por meio da radiodifusão, como forma de auxiliar o país no combate aos altos índices de analfabetismo constatados no período.

Oficialmente, a EaD passou a ser considerada e reconhecida como modalidade de ensino com a Lei no 9.394, de 20 de dezembro de 1996, que estabelece as diretrizes e bases da educação nacional (BRASIL, 2017). Mendonça et al. (2012), afirma que o avanço da EaD pode ser identificado pelo aumento das ofertas nas instituições públicas e particulares (privadas), o que representa a expansão de uma perspectiva educacional inovadora em concordância com a nova sociedade que vivencia a geração das novas tecnologias.

Diante dessa expansão do ensino superior brasileiro e sua interiorização, promovida por políticas governamentais, as instituições de ensino superior foram estimuladas a utilizar os recursos tecnológicos e passaram a adotar a EaD como forma de aprimorar o modo de gerar e proporcionar o conhecimento (CASSUNDÉ, MENDONÇA, 2014).

Silva e Nunes (2014) argumentam sobre as diferentes opiniões voltadas para esse tipo de ensino, pois, segundo eles, há um grupo de entusiastas que aprovam o uso das tecnologias da informação e comunicação para atualizar os processos de ensinar e aprender, em contrapartida, existem os que defendem a impossibilidade de um estudante aprender com qualidade em frente a tela de um aparelho multimídia. Apesar das opiniões contrárias, a EaD tem se mostrado eficiente no processo de aprendizagem, pois ela oferta cursos de graduação, pós-graduação, técnicos profissionalizantes e aperfeiçoamento.

De um modo geral, o preconceito em relação à EaD está diminuindo, à medida que pesquisas relatam a seriedade dos profissionais envolvidos e a satisfação dos estudantes (TEPERINO, 2006). Mesmo com a resistência por parte de algumas pessoas, Silva e Nunes (2014) afirmam que o ensino passou a ser uma alternativa estratégica com o intuito de fornecer "educação para todos".

Além disto, a EaD tem proporcionado modelos de ensino inovadores e cada vez mais vem consquistando espaço nos cursos de graduação e de pós-graduação do país. Borges (2015) afirma que, a demanda pelos cursos online de graduação têm aumentado significativamente, há cada vez mais matrículas de estudantes, que enfrentam o desafio de aprender com a experiência para avaliar e incentivar a inovação educacional. 


\section{Discursos teóricos sobre a atuação dos tutores na $\mathrm{EaD}$}

Com o desenvolvimento da EaD, a presença de profissionais para orientar e mediar os estudantes nesse processo educativo passa a ser essencial. Neste contexto, segundo Caetano e Rezende Júnior (2009), é fortalecido o papel dos tutores nos cursos, pois são atores que estabelecem contatos mais efetivos com os estudantes.

Nas palavras dos autores supracitados "O tutor atua tanto junto ao corpo docente, participando diretamente da prática pedagógica, como também está em contato com os alunos. O tutor possui, portanto, ampla visão do curso e de todos os seus elementos" (CAETANO; REZENDE JUNIOR, 2009, p. 1).

Para Oliveira e Lima (2012), o tutor presencial é aquele agente que se faz presente no polo de apoio presencial da Universidade Aberta do Brasil (UAB), responsável pela interlocução entre os estudantes e a instituição formadora, ao qual são atribuídas funções específicas para viabilizar a formação por meio da EaD.

O papel desempenhado pelos tutores é fundamental para que os cursos tenham um bom desenvolvimento. No entanto, Segenreich (2009) considera que a figura do tutor é pouco reconhecida, uma vez que ocorre de maneira precária, informal e sem vínculos empregatícios, o que faz da tutoria uma espécie de "subclasse docente".

Para a instituição do curso investigado nesse estudo, as atribuições dos tutores presenciais contemplam realizar instruções básicas no campo da informática, ou seja, orientar os estudantes na navegação no Ambiente Virtual de Aprendizagem (AVA), além de auxiliar na execução de tarefas e apoiar a coordenação do curso operacionalmente nas atividades presenciais que acontecem nos polos da UAB, especialmente no acompanhamento dos fóruns de dúvidas e na aplicação de avaliações (IFMT, 2013).

Contudo, geralmente os tutores precisam assumir, além das funções burocráticas e de assistência técnica, os aspectos pedagógicos que envolvem algumas determinadas disciplinas (SEGENREICH, 2009). Isto acontece no intuito de suprir as lacunas deixadas pelos professores formadores que nem sempre podem suprir as dúvidas devido às limitações espaciais. Além disso, o apoio na realização de tarefas das disciplinas e o acompanhamento de estudos em grupos fazem com que os tutores presenciais exerçam atividades que competem aos formadores.

Quando ocorre a intervenção pedagógica do tutor, esse ator desempenha o papel de coformador, o que caracteriza um processo de polidocência. Nas palavras de Oliveira e Lima (2012, p.85), um "coletivo de trabalhadores que, mesmo com funções diversas, é responsável pelo processo de ensino-aprendizagem na educação a distância (...) quem ensina na educação a distância é um polidocente".

Nesse sentido, os tutores assumem a tarefa de tirar dúvidas relativas aos conteúdos abordados nas disciplinas que compõem o currículo do curso, no exercício da polidocência. Trata-se inclusive de uma atividade complexa, pois demanda articulação com as diversas áreas do conhecimento numa perspectiva interdisciplinar.

Além disso, geralmente o tutor apresenta uma formação generalista vinculada à área do curso e não a uma única disciplina, o que pode provocar trabalho intensivo e até levar a um possível desgaste físico e mental. Por este motivo que Acosta et all. (2015) defendem que os tutores necessitam receber formação específica e sejam mais valorizados devido à importância do papel que exercem, pois também são responsáveis pela formação dos futuros professores de química da educação básica. 
Segundo os estudos de Alonso (2010, p.1330) "o tutor não tem profissionalmente reconhecimento social/econômico/empregatício compatível com suas atribuições, embora seja ele, também o responsável pelo atendimento mais próximo aos alunos". Em outras palavras, mesmo não sendo reconhecidos, os tutores são fundamentais, pois participam do processo formativo, viabilizado pela EaD, de maneira que possam interagir não apenas com os estudantes, mas também com todos os atores envolvidos, ou seja, esses profissionais exercem uma espécie de elo entre professores formadores, coordenadores do curso e polo $\cup A B$ e os estudantes do respectivo curso.

Segundo Caetano e Rezende Junior (2009), os tutores desempenham um papel central nos cursos de formação via modalidade EaD, pois atuam de forma conjunta com os professores formadores, intermediando as práticas pedagógicas com os estudantes. Para os autores, estes profissionais possuem uma visão ampla sobre o desenvolvimento do curso, por isso defendem a necessidade de ouvi-los para buscar compreender a situação mais fidedigna do andamento do processo formativo em EaD, pois tais informações poderão orientar ações futuras que promovam a melhoria dos cursos.

\section{Procedimentos metodológicos}

A presente pesquisa configura-se como descritiva e exploratória, com abordagem qualitativa. No entendimento de Creswell (2010), pesquisa com abordagem qualitativa é aquela em que o pesquisador procura estabelecer o significado de determinado fenômeno a partir do ponto de vista dos participantes envolvidos na investigação.

O objeto de estudo escolhido para investigação é o Curso de Licenciatura em Química, ofertado na modalidade EaD pelo IFMT Campus Cuiabá - Bela Vista. Seu desenvolvimento ocorreu no primeiro semestre de 2018. Delimitou-se neste texto, o levantamento das percepções que os tutores presenciais possuem sobre o andamento do processo formativo.

O curso é ofertado atualmente em oito polos de apoio presencial da UAB, localizados em oito diferentes municípios mato-grossenses, a saber: Alto Araguaia, Barra do Bugres, Cuiabá, Diamantino, Juara, Pontes e Lacerda, Ribeirão Cascalheira e Sorriso. A quantidade de tutores presenciais varia entre um e cinco, conforme a quantidade de turmas ofertadas e estudantes matriculados. Esta distribuição do quantitativo de tutores por polo pode ser visualizada no Quadro 1.

Quadro 1: Quantitativo de tutores presenciais por polo da UAB.

\begin{tabular}{l|c|l|c}
\hline $\begin{array}{c}\text { Polo de apoio presencial } \\
\text { da UAB }\end{array}$ & $\begin{array}{c}\text { Quantidade de } \\
\text { Tutores }\end{array}$ & $\begin{array}{c}\text { Polo de apoio presencial } \\
\text { da UAB }\end{array}$ & $\begin{array}{c}\text { Quantidade de } \\
\text { Tutores }\end{array}$ \\
\hline Alto Araguaia & 01 & Juara & 01 \\
\hline Barra do Bugres & 02 & Pontes e Lacerda & 03 \\
\hline Cuiabá & 05 & Ribeirão Cascalheira & 01 \\
\hline Diamantino & 01 & Sorriso & 02 \\
\hline
\end{tabular}

Os contatos telefônicos e endereços eletrônicos dos tutores presenciais que atuam no curso foram fornecidos pela coordenação de tutoria, tendo sido autorizada pelo coordenador do curso. Aos 16 (dezesseis) tutores, inicialmente foi enviado um material contendo informações gerais sobre os propósitos do estudo, os procedimentos a serem realizados, as garantias de confidencialidade e de esclarecimentos permanentes. 
Também foi enviado o Termo de Consentimento Livre e Esclarecido (TCLE) para todos e aqueles que concordassem participar voluntariamente da pesquisa, assinaram e retornaram no formato digital. O convite foi enviado via endereços eletrônicos por mais de duas vezes, sendo que o mesmo foi reforçado pelo coordenador do curso. Além disso, também foi tentado contato telefônico para a participação tornar-se expressiva. Buscando garantir o anonimato dos envolvidos, seus nomes foram substituídos por algarismos alfanuméricos, da seguinte maneira: Tutor Presencial 1 (TP1), Tutor Presencial 2 (TP2) e assim sucessivamente.

Foram oito, os tutores participantes da pesquisa. Dentre eles, três possuem formação em Licenciatura em Química, dos quais um deles formou-se no próprio curso em que atua. Outros dois são licenciados em Ciências Biológicas, outros dois em Física e um tutor possui como formação bacharelado em Administração de Empresas, mas além de tutor é estudante do curso investigado desde 2014, ou seja, está prestes a concluir a licenciatura na área.

Todas as instituições formadoras destes tutores são mato-grossenses, sendo elas a Universidade Federal de Mato Grosso (UFMT) responsável pela formação acadêmica de três tutores, a Universidade de Cuiabá (UNIC), responsável pela formação de outros dois, a Universidade do Estado de Mato Grosso (UNEMAT) formou um destes tutores, o Centro Universitário de Várzea Grande (UNIVAG)formou outro deles, além do IFMT que já formou um dos tutores neste curso em EaD e está prestes a formar outro que não possuía formação em licenciatura.

Referente ao tempo de atuação na tutoria, dois desses tutores estão atuando no curso desde 2009, um deles iniciou em 2010, um em 2014, outros dois em 2015, outro em 2016 e um deles iniciou as atividades de tutoria em 2017. Dentre os participantes, dois deles já tinham experiência na tutoria de cursos em EaD, um deles em nível de graduação e o outro em nível de especialização Lato Sensu. Cabe aqui registrar que apenas um dos participantes não atua na docência como professor da Educação Básica e que todos os demais desempenham a função de professores na rede pública de ensino além da atividade de tutoria no curso.

Para alcançar o objetivo estabelecido, foi utilizado como instrumento na coleta de dados um formulário eletrônico (Google Forms). A opção por esse tipo de instrumento eletrônico deu-se devido o meio virtual ser bastante utilizado na comunicação entre os atores da EaD, além da considerável dispersão geográfica dos mesmos.

O formulário foi constituído por seis questões abertas, das quais uma delas serviu para caracterizar o público participante e as demais se relacionavam às percepções que possuem sobre o curso. Foram respondidas as seguintes questões: 1) Descreva sua formação acadêmica, e sua trajetória profissional, principalmente relacionada à atuação na tutoria do curso. 2) Comente como são as relações estabelecidas entre os atores da EaD e como se estabelece a comunicação nesse curso de Licenciatura em Química. 3) Cite os principais desafios enfrentados para desempenhar a tutoria em um curso de formação de professores de química em EaD. 4) Cite as principais dificuldades dos estudantes que você observa no decorrer do curso. 5) Em sua percepção, quais são as lacunas para a formação docente existentes nesse Curso de Licenciatura em Química? 6) Cite e comente quais habilidades e conhecimentos que esse curso de licenciatura está proporcionando aos futuros professores de química. 
A metodologia utilizada para analisar os resultados é a análise de conteúdo, proposta por Bardin (2012). De acordo com a autora, esse método possibilita extrair das palavras fornecidas pelos sujeitos investigados, a mensagem contida relacionada ao assunto em estudo. A categorização ocorreu de maneira emergente e frequencial, sendo que, realizouse o agrupamento de mensagens semelhantes na tabulação dos dados. A discussão dos resultados foi realizada com a sustentação dos aportes teóricos utilizados.

\section{Resultados e discussões}

Das respostas emitidas pelos oito tutores participantes, emergiram três categorias: Desafios existentes neste processo formativo; Dificuldades ou lacunas identificadas no decorrer do curso; e Conhecimentos proporcionados aos futuros professores de química. De cada categoria emergiram subcategorias, conforme esquematizado no Quadro 2.

Quadro 2: Esquema da organização dos resultados

\begin{tabular}{|c|c|c|}
\hline Categorias & Subcategorias & Fontes/Questões \\
\hline \multirow{3}{*}{$\begin{array}{l}\text { Desafios existentes } \\
\text { neste processo } \\
\text { formativo }\end{array}$} & Interlocução entre os atores & \multirow{3}{*}{$\begin{array}{c}\text { 2) Comente como são as relações } \\
\text { estabelecidas entre os atores da EaD e } \\
\text { como se estabelece a comunicação neste } \\
\text { curso de Licenciatura em Química. } \\
\text { 3) Cite os principais desafios enfrentados } \\
\text { para desempenhar a tutoria em um curso } \\
\text { de formação de professores de química em } \\
\text { EaD. }\end{array}$} \\
\hline & $\begin{array}{c}\text { Problemas estruturais do } \\
\text { curso }\end{array}$ & \\
\hline & $\begin{array}{c}\text { Falta de compromisso dos } \\
\text { estudantes }\end{array}$ & \\
\hline \multirow{3}{*}{$\begin{array}{l}\text { Dificuldades ou } \\
\text { lacunas identificadas } \\
\text { no decorrer do curso }\end{array}$} & Despreparo dos estudantes & \multirow{3}{*}{$\begin{array}{l}\text { 4) Cite as principais dificuldades dos } \\
\text { estudantes que você observa no decorrer } \\
\text { do curso. } \\
\text { 5) Em sua percepção, quais são as lacunas } \\
\text { para a formação docente existentes nesse } \\
\text { Curso de Licenciatura em Química? }\end{array}$} \\
\hline & Problemas na comunicação & \\
\hline & $\begin{array}{c}\text { Carência de atividades } \\
\text { experimentais }\end{array}$ & \\
\hline \multirow{2}{*}{$\begin{array}{l}\text { Conhecimentos } \\
\text { proporcionados aos } \\
\text { futuros professores de } \\
\text { química }\end{array}$} & $\begin{array}{c}\text { Habilidades vinculadas a } \\
\text { formação via EaD }\end{array}$ & \multirow{2}{*}{$\begin{array}{l}\text { 6) Cite e comente quais habilidades e } \\
\text { conhecimentos que esse curso de } \\
\text { licenciatura está proporcionando aos } \\
\text { futuros professores de química. }\end{array}$} \\
\hline & $\begin{array}{l}\text { Conhecimentos específicos } \\
\text { para atividade profissional }\end{array}$ & \\
\hline
\end{tabular}

A primeira categoria discorre sobre os desafios existentes no processo de formação inicial de professores de química deste curso em EaD. A categoria emergiu das respostas dadas ao segundo e terceiro questionamentos do formulário eletrônico. Foram três as subcategorias identificadas como desafios: a interlocução entre os atores, os problemas estruturais do curso e a falta de compromisso dos estudantes.

Os desafios referentes à interlocução dos envolvidos ficam evidenciados nas seguintes respostas fornecidas pelos tutores do curso: "Existem outros desafios na EaD como problemas no sistema, prazos de atividades, comunicação entre estudantes e professores, mas isso é comum a todos os cursos ofertados nessa modalidade" (TP3). "Um deles é a comunicação entre todos segmentos que ocorre mais virtualmente. Os professores precisam ser mais eficientes nas respostas para dúvidas sobre conteúdo ou notas" (TP5). 
A relação entre os estudantes e os professores formadores é tímida. É preciso conhecer os alunos, se aproximar deles a ponto de conquistar a confiança deles, suprindo o lado afetivo que o ser humano precisa. Chamar e conversar com ele para verificar as causas da não participação ou desistência nos finais de semestre para poder orientá-los da melhor forma possível (TP7).

"Os alunos deveriam utilizar a plataforma de maneira mais efetiva, pois fazem por telefone ou por e-mail, mas para fins de registro deveriam utilizar mais a plataforma para diagnosticar e realizar futuras intervenções" (TP4). "A comunicação às vezes é conturbada, principalmente entre professores e estudantes, pois há muita falta de feedback o que dificulta ainda mais o Curso, pois o processo de aprendizagem é conduzido a partir dessa troca (TP6). A relação quase sempre é hierárquica" (TP8).

Como é possível observar, a subcategoria que aponta a comunicação como um desafio a ser enfrentado foi a mais recorrente entre os tutores participantes da investigação. No entanto, espera-se que não fique somente no campo da constatação e sim que aconteçam ações efetivas por parte dos tutores presenciais do curso, pois são eles os agentes responsáveis pela interlocução dos demais atores envolvidos no processo formativo em EaD (CAETANO; REZENDE JUNIOR, 2009; OLIVEIRA; LIMA, 2012).

O desafio da melhoria na comunicação entre os atores da EaD é uma necessidade para que os cursos proporcionados pela modalidade atinjam seus objetivos, ou seja, para que a política de acesso e permanência no Ensino Superior ocorra de fato, é preciso que o diálogo favoreça o processo educativo (SILVA; NUNES, 2014; CASSUNDÉ, MENDONÇA, 2014; BORGES, 2015).

Cabe ressaltar que o preconceito existente sobre os cursos ofertados na modalidade EaD, de acordo com Teperino (2006), diminui à medida que os estudantes em processo de formação sentem-se satisfeitos com a atenção recebida, ao perceberem a seriedade dos envolvidos neste processo formativo. Contudo, a interlocução entre os envolvidos precisa ser plena, ou seja, essa lacuna identificada pelos tutores do curso investigado, precisa ser superada.

Sobre os problemas estruturais do curso, os tutores apontaram: "Os desafios estão mais voltados para a administração do curso e atendimento a tudo que se propõe na EaD, ou seja, zelar para cumprir todas etapas: aulas de laboratório, fóruns presenciais, sala de conferências e outras atividades" (TP1). "Exercer funções coadjuvantes é um desafio, além disso é muito baixa a remuneração paga para o exercício dessa função. Assumimos um importante papel nesse processo. Os estudantes confiam e partilham muitas coisas conosco, sejam angústias, sejam conquistas ou até suas percepções sobre o andamento do curso" (TP2).

"Acredito que um dos principais desafios seja a própria complexidade dessa ciência, que exige abstração, conhecimentos de cálculos e também quanto às atividades experimentais" (TP3). "Como minha formação é em Química poderia ser dada uma atenção maior, oportunizando qualificação principalmente nas atividades práticas, pois fortaleceria ainda mais o processo de aprendizagem, além de ajudar nos custos de formação dos estudantes" (TP5). "Os desafios estão em torno da necessidade das aulas presenciais que os conteúdos da formação de química exigem" (TP8).

Conforme o relato de TP5, é possível confirmar a preocupação sobre precarização do trabalho docente pela redução do professor a tutor apontada por Acosta et al. (2015), pois 
é perceptível que os tutores desse curso acabam desempenhando atribuições que competem aos professores formadores, caracterizando a polidocência descrita por Oliveira e Lima (2012).

No estudo de Oliveira et. al. (2013) os tutores também admitem assumir em determinadas situações a mediação pedagógica, inclusive recorrendo a orientações advindas da psicologia. Não que um profissional com conhecimentos na área do curso não possa contribuir com a formação, pelo contrário, mas ao se responsabilizar pela ação formativa como relatado, fica evidente que não está claro quais são as funções da tutoria que, segundo a própria instituição formadora, não atribui tal competência aos tutores (IFMT, 2013).

Referente à falta de compromisso dos estudantes, seguem algumas respostas: "O maior desafio no curso é contribuir para a autonomia do aluno" (TP1). "Outro desafio é o elevado índice de evasão dos alunos desse curso, principalmente quando se deparam com as dificuldades nos estudos, sejam elas técnicas ou na complexidade dos assuntos" (TP2). "O comprometimento com o estudo, pois o curso a distância requer autodisciplina, gerenciamento do tempo e uma densidade de interesse por parte do aprendiz para que tenham êxito em sua jornada, é de extrema relevância" (TP7).

A constatação de que os estudantes do curso apresentam mais dificuldades no campo formativo do que no técnico, também foi identificada no estudo de Oliveira et al. (2013). Segundo os autores, no caso do curso de Licenciatura em Química em EaD da UFMG, são apontados como principais desafios no exercício da tutoria, apoiar e orientar os estudantes no decorrer do processo formativo para que obtenham êxito em seus estudos.

A segunda categoria contempla as dificuldades ou lacunas identificadas no decorrer do curso. Os dados referentes a esses importantes aspectos foram obtidos por meio do quarto e quinto questionamento do formulário, dos quais emergiram as seguintes subcategorias: despreparo dos estudantes, problemas na comunicação e carência de atividades experimentais.

Sobre o despreparo dos estudantes, as respostas dos tutores foram: "Os estudantes aprenderem usar a plataforma, pois muitos não conseguem enviar atividades" (TP1). "Os estudantes precisam manter uma rotina de estudos frente ao trabalho e vida pessoal e utilizar melhor as ferramentas da plataforma: Fórum, mensagem, comunicação" (TP5).

Os estudantes dos primeiros semestres têm muitas dificuldades quanto ao sistema, quanto à postagem das atividades, quanto ao cumprimento de prazos, enfim, dificuldades para compreender como funciona um curso a distância. Com o avanço dos semestres, as dificuldades ficam mais centradas nos conceitos mesmo, principalmente na compreensão das disciplinas que envolvam cálculos (TP3).

"Considero que os alunos se formam com muitos conhecimentos científicos e pouca aprendizagem docente, faltam atividades pragmáticas de docência para que se formem realmente professores" (TP6). "A maioria dos alunos é totalmente despreparada ou nunca tiveram professor qualificado na área no Ensino Médio. Falta de leitura, querem as coisas com facilidade sem muitos esforços, poucos fazem boas pesquisas e se preparam para as provas" (TP7).

Similar constatação obteve Caetano e Rezende Junior (2009), pois os tutores investigados nesse estudo em um curso de formação inicial de professores da UNIFEI, desenvolvido na modalidade EaD, apontaram que a maioria dos estudantes que 
acompanham são desinteressados, apresentam lacunas formativas anteriores, assistem passivamente as atividades proporcionadas pelo curso e que, apenas uma minoria deles, está realmente comprometida com os estudos e participa ativamente das atividades propostas.

$\mathrm{Na}$ investigação realizada por Oliveira et al. (2013), no curso de Licenciatura em Química da UFMG, os tutores presenciais apontaram como as duas maiores dificuldades enfrentadas pelos estudantes: a pouca ou inexistente autonomia deles para estudar e a formação precária que antecedeu o ingresso no curso. Segundo os tutores da UFMG, faltam muitos conhecimentos básicos da química, dos cálculos matemáticos e de interpretação de textos, dificultando o desenvolvimento das atividades.

Referindo-se aos problemas de comunicação identificados no curso, os tutores evidenciaram: "Falta feedback dos professores, cumprimento de datas para correções, falta de coordenação pedagógica, falta de fóruns presenciais em disciplinas específicas" (TP1). "Problemas estruturais como os professores despejarem muita matéria num só momento sem explicação da mesma, atraso no início de cada semestre do curso. O calendário acadêmico sempre muda o que foi proposto" (TP2). "Falta feedback dos professores e poucas aulas presenciais e vídeos-conferências" (TP4). "A questão dos estágios supervisionados é complicada, sem acompanhamento por parte de um professor de estágio. Os acadêmicos ficam todos perdidos" (TP8).

Nos estudos de Oliveira et al. (2013), os tutores, baseados em suas próprias experiências na Licenciatura em Química em EaD, sugerem que é preciso ocorrer melhorias na comunicação e combinados do curso, o que, segundo os investigados naquele estudo, parece ser o maior entrave para o sucesso e bom andamento do curso. Os fatores que interferem na comunicação vão desde problemas com a rede de internet, passando pela ausência ou baixa participação dos estudantes no ambiente virtual, culminando com desencontros de horários ou indisponibilidade dos professores formadores no momento de tirar dúvidas.

Essas dificuldades também confirmam as constatações realizadas por Acosta et al. (2015) nesse curso: os tutores acabam assumindo diversas responsabilidades para suprir lacunas, inclusive de aspectos formativos, e essa sobrecarga pode tornar o ensino mais frágil. A precarização do trabalho docente pela redução de professor a tutor, combatida pelos autores, pode influenciar negativamente na formação dos futuros professores de química.

Outra lacuna apontada pelos tutores deste curso é a questão das poucas aulas de atividades experimentais. Algumas respostas foram: "Uma das lacunas nesse processo formativo é a questão experimental, pois considero insuficiente ocorrer duas ou três aulas práticas no decorrer de todo um curso de química, que é uma ciência experimental" (TP3). "Pouca execução de aulas práticas pela IES que deveria ter maior comprometimento em oferecer e garantir a qualidade do curso" (TP4). "Disponibilidade de mais aulas práticas através de oficinas mensais pelo menos, maior vivência prática de experimentos em sala de aula desde o início do curso" (TP5). "Nas disciplinas exatas e de experimentação os estudantes ficam perdidos na aplicação desses conhecimentos no cotidiano devido terem pouco contato" (TP6).

De fato a química é uma ciência com caráter experimental, ou seja, é primordial que a experimentação seja explorada e desenvolvida nos cursos de formação inicial de química. Essa lacuna não foi identificada por Silva e Fireman (2013) na Licenciatura em Química da 
UFRN, pois naquele curso ocorrem atividades experimentais regularmente. Porém, no referido estudo a preocupação se concentrou na racionalidade técnica, durante a realização de atividades experimentais, devido à influência dos tutores do curso.

A terceira e última categoria contempla os conhecimentos proporcionados aos futuros professores de química. Das respostas fornecidas para a sexta questão do formulário, emergiram duas subcategorias: habilidades vinculadas a formação via EaD e conhecimentos específicos para atividade profissional.

Os tutores participantes relataram algumas habilidades vinculadas à formação por EaD: "A proposta da Educação a Distância é, sem dúvida, ótima para uma formação que capacita de maneira autônoma para o fazer pedagógico" (TP4). "Autonomia para os formados pelo curso, que se esforçam mesmo e utilizam as possibilidades da plataforma, o conteúdo pertinente, professores que mostram ter capacidade técnica/formação" (TP5).

Devido ao fato do curso ser em EaD muitas aprendizagens são viabilizadas, pois os estudantes aprendem na prática a pesquisar, a estudar, a pensar de forma crítica e a desenvolver mecanismos para solucionar problemas. Outro aspecto importante é a questão dos estágios, pois é vivenciando o chão da escola que muitos ensinamentos são possíveis (TP2).

"A aprendizagem proporcionada pelo curso em EaD prepara para lidar com diferentes situações, a exemplo da coletividade criada pelas necessidades em comum no decorrer do curso, o que os aproxima para trabalhar em grupo" (TP6).

A habilidade da autonomia foi um dos aspectos apontados por Oliveira et al. (2013) extremamente necessário para os professores de química formados por cursos em EaD. Os autores acreditam que esse importante aspecto vai sendo desenvolvido ao longo do curso, por meio do planejamento e gerenciamento dos próprios estudos.

Contudo, o desenvolvimento dessa habilidade específica requer dedicação, interesse e compromisso dos estudantes em formação. Segundo a instituição formadora, essas são algumas das habilidades esperadas dos estudantes formados pela EaD, que unidas à motivação intensa, pelo senso de responsabilidade, pela pró-atividade e autodisciplina, possibilitam constituir um profissional preparado para desempenhar suas funções de maneira efetiva (IFMT, 2013).

Sobre os conhecimentos específicos para atividade profissional, foram apontados pelos tutores: "Considero que são as mesmas habilidades e conhecimentos que podem ser adquiridos na educação presencial" (TP1). "Conhecimentos científicos, o que tem ajudado muito as escolas com falta desse profissional na área de ciências, disciplina de Química" (TP7).

Conhecimentos na área de referência: acredito que o curso tenha proporcionado aprendizados nos conceitos científicos que envolvem a química. Conhecimentos na área pedagógica: como exercer a função docente, desde a postura, o planejamento, as estratégias de ensino, a transposição didática e a avaliação da aprendizagem (TP3).

Estes resultados reforçam o pensamento de Silva e Fireman (2013) que defendem uma licenciatura em química capaz de superar a racionalidade técnica e ao mesmo tempo proporcione a racionalidade prática promovendo a formação de profissionais melhores preparados para atuar na educação básica. 
De modo geral, percebe-se que o curso investigado possibilita formação específica, mas que necessita de reflexões sobre o processo formativo e adequações quando forem necessárias, pois segundo Silva e Fireman (2013, p. 72): "não é possível formar bons professores a partir da fragmentação e da busca pelo acúmulo de conhecimentos teóricos específicos e pedagógicos desvinculados entre si e longe da realidade das escolas".

\section{Considerações finais}

Neste texto foram apresentadas as perspectivas dos tutores presenciais que atuam no curso de Licenciatura em Química do IFMT, ofertado na modalidade EaD, sobre importantes aspectos relacionados a como está sendo desenvolvida essa formação inicial específica. A visão que os tutores compartilharam sobre o curso constitui-se uma preciosa fonte de informações que poderá orientar ações para promover melhorias nesse curso e compreender como está ocorrendo a formação de professores de química via EaD.

Sobre os desafios existentes nesse processo formativo, os participantes evidenciaram a interlocução entre os atores, os problemas estruturais do curso e a falta de compromisso dos estudantes. Tais desafios necessitam ser superados por meio de ações pensadas em conjunto pela coordenação do curso, pelos professores formadores e pelos tutores presenciais que acompanham o processo de maneira mais próxima aos estudantes. Todavia, é preciso ter cuidado para que a tutoria não assuma atribuições que não lhe competem.

O despreparo dos estudantes, os problemas na comunicação e a carência de atividades experimentais foram as dificuldades ou lacunas identificadas pelos tutores no decorrer do referido curso. A formação precária dos estudantes pode estar atrelada ao fato de terem passado por professores sem formação específica em química na educação básica, o que exige dos professores formadores pensarem uma maneira de superar as dificuldades conceituais. Referente à experimentação, cabe à instituição formadora proporcionar que ela aconteça de maneira efetiva no decorrer desse processo formativo.

Quanto aos conhecimentos proporcionados aos futuros professores de química, os tutores apontam importantes habilidades vinculadas à formação via EaD, a exemplo da autonomia e da disciplina, além de conhecimentos específicos para desempenhar a função de professores de química.

São possíveis desdobramentos e sugestões para pesquisas futuras: investigar as percepções dos acadêmicos em formação, dos egressos formados, bem como um levantamento de recursos e estratégias disponíveis para a formação inicial de professores de química em EaD. O processo formativo é dinâmico e fundamental, por isso, a temática é propícia para o desenvolvimento de constantes pesquisas.

Formar bons professores de química é uma necessidade na sociedade contemporânea, até mesmo porque o resultado será refletido nas salas de aula das escolas brasileiras. Portanto, oportunizar formação inicial de professores de química por meio da modalidade EaD é uma maneira de contribuir para a qualidade da educação, mas para que isso aconteça todos os envolvidos precisam estar em sintonia, de maneira que estudantes, professores formadores, tutores presenciais e coordenação do curso dialoguem e construam juntos os saberes necessários para o exercício da docência. 


\section{Referências}

ACOSTA, C. L. C.; DESTRO, A. P. M.; FERREIRA, M.; YAMIL, N. De professores a tutores: processos de precarização do trabalho docente pela modalidade EAD. In: Seminário Educação 2014 - Educação e seus sentidos no mundo digital. Anais... Cuiabá: EdUFMT, p. 2146-2160, 2015.

ALONSO, K. M. A expansão do ensino superior no Brasil e a EaD: dinâmicas e lugares. Educ. Soc. Campinas, v. 31, n. 113, p. 1319-1335, out.-dez. 2010. Disponível em: <http://www.scielo.br/pdf/es/v31n113/14.pdf> Acesso em: 18 jun. 2018.

BARDIN, L. Análise de conteúdo. São Paulo: Edições 70, 2012.

BORGES, F. A. F. A EaD no Brasil e processo de democratização do acesso ao ensino superior: diálogos possíveis. Revista Científica em Educação a Distância, v. 5, n. 3, 2015.

BRASIL, Lei no 9.394, de 20 de dez de 1996. Disponível em: < http://www2.camara.leg.br/legin/.../lei/.../lei-9394-20-dezembro-1996-362578-normapl.http> Acesso em: 18 de ago de 2017 às 19h.

CAETANO, T. C.; REZENDE JUNIOR, M. F. A visão dos tutores no curso de licenciatura em física, modalidade a distância, da Universidade Federal de Itajubá - MG. In: XVIII Simpósio Nacional de Ensino de Física, 2009, Vitória-ES. Atas... São Paulo: Editora da SBF, 2009.

CASSUNDÉ, F. R. S. A.; MENDONÇA, J. R. C. A virtualização do ensino superior: uma análise do contexto brasileiro. Revista EaD em foco, Fundação Cecierj - v. 4, n. 1. Rio de Janeiro Junho, 2014.

CRESWELL, J. W. Projeto de pesquisa: método qualitativo, quantitativo e misto. 3. ed. Porto Alegre: Artmed, 2010.

IFMT. Manual do Aluno EAD. Instituto Federal de Mato Grosso - Departamento de Educação à Distância. Cuabá/MT: DEAD, 2013. Disponível em:

$<$ http://ead.ifmt.edu.br/media/filer_public/3f/0f/3f0fd110-6f0e-487e-9c1e-

7265759c1719/manual_do_aluno_uab-ifmt.pdf> Acesso em: 12 nov. 2017.

MENDONÇA, J. R. C.; PAIVA, KELY, C. M.; PADILHA, M. A.; BARBOSA, MILKA A. C.;

MARTINS, M. A. B. Competências eletrônicas de professores para Educação a Distância no

Ensino Superior no Brasil: discussão e proposição de modelo de análise. In: Fórum da

Gestão do Ensino Superior nos Países e Regiões de Língua Portuguesa, 2012.

OLIVEIRA, F. P. M.; LIMA, C. M. Tutoria e docência no ensino superior a distância:

aproximações e distanciamentos. In: I Simpósio Internacional de Educação a Distância e I

Encontro de Pesquisadores em Educação a Distância (SIED-EnPED), 2012.Anais...São Carlos:

UFSCar, p. 1-12, 2012. Disponível em: <http://sistemas3.sead.ufscar.br/ojs/Trabalhos/310-

924-1-ED.pdf> Acesso em: 07 jun. 2018.

OLIVEIRA, I. M. F.; QUADROS, A. L.; TOFANI, S.F.B.; FERREIRA, A. C.; COUTO, L. G. O. O tutor do curso de Licenciatura em Química da UFMG: reflexões a partir do que percebe. Revista Iberoamericana de Educación a Distancia, v. 16, p. 133, 2013.

SANTOS, B. F. Ensino de Química em diferentes contextos sociais. Amazônia (UFPA), v. 13, p. 104-118, 2017. 
SEGENREICH, S.C. D. ProUni e a UAB como estratégias de EAD na expansão do Ensino Superior. Pro-Posições. Campinas, v.20, n.2 (59), p.205-222, maio/ago. 2009. Disponível em:<http://www.scielo.br/pdf/pp/v20n2/v20n2a13.pdf> Acesso em: 21 maio 2018.

SILVA, F. A. S.; FIREMAN, E. C. Estudo de Caso da Formação de Professores da Licenciatura em Química na Modalidade Ead da UFRN: reflexos da formação alicerçada na racionalidade técnica dos tutores. EAD em Foco, v. 3, p. 68-81, 2013.

SILVA, J. B.; NUNES, C. P. Políticas de formação de professores na modalidade da educação a distância no Brasil. Revista EDaPECI, São Cristovão, v. 14, n. 3, p. 455-469, set/dez 2014.

TEPERINO, A. S. Educação a distância em organizações públicas. Brasília: Escola Nacional de Administração Pública, 2006. 